\section{Effect of Sonic Vibrations on Bond Strength of Fiberglass Posts Bonded to Root Dentin}

Amanda Mahammad Mushashe, Rodrigo Otavio Jatahy Ferreira do Amaral, Carlos Eduardo Edwards Rezende, Flares Baratto Filho, Leonardo Fernandes da Cunha, Carla Castiglia Gonzaga
UP - Universidade Positivo, Graduate Program in Dentistry, Curitiba, PR, Brazil

Correspondence: Carla Castiglia Gonzaga, Rua Professor Pedro Viriato Parigot de Souza 5300, 81280-330 Curitiba, PR, Brasil. Tel: +55 41 3317-3403. e-mail: carlacgonzaga2@gmail.com

\begin{abstract}
Sonic vibrations may improve the bond strength and durability of fiberglass posts by improving adhesive penetration into dentin as well as the cement flow. The objective of this study was to evaluate the effect of sonic vibrations on the bond strength between fiberglass posts and root dentin using the pull-out test. Bovine roots were endodontically treated and divided randomly into four groups $(n=12)$ : Group C - conventional cementation (control); Group SA - sonic vibration (Smart Sonic Device, FGM) of the adhesive system and conventional post accommodation; SP group - conventional adhesive application and sonic vibration of the post during accommodation; and SASP - sonic vibration of the system adhesive and the post during accommodation. The posts were cleaned, treated with a silane and adhesive system (Ambar, FGM), and cemented with a dual-cured resin cement (Allcem Core, FGM). After $24 \mathrm{~h}$, the specimens were subjected to mechanical tests and failure analyses. Representative specimens were analyzed by a scanning electron microscope to observe the cementation line. The results were analyzed using ANOVA and Tukey's test $(\alpha=5 \%)$. The bond strengths were as follows: SASP $(90.9 \pm 27.1 \mathrm{~N}), \mathrm{C}$ $(121.4 \pm 60.6 \mathrm{~N}), \mathrm{SA}(127.6 \pm 31.8 \mathrm{~N})$ and SP $(156.4 \pm 41.3 \mathrm{~N})$. The use of sonic vibrations during the application of adhesive or post cementation separately did not affect the bond strength but had a negative effect when used for both procedures.
\end{abstract}

Key Words: dental materials, post and core technique, dental restoration failure.

\section{Introduction}

Fiberglass posts are widely used in the restorative treatment of endodontically treated teeth (1-3). However, establishing the most appropriate adhesive cementation technique for fiberglass posts is still a challenge (4-6), since the main cause of the failures is their displacement (7-10). Factors such as the cementation technique and used material as well as operator's skill affect the long-term stability of the hybrid layer (4-6).

Recently, studies have shown that the active and vigorous application of the adhesive system improves its immediate and long-term performance, as it results in the evaporation of a greater amount of solvents in the adhesive as well as greater penetration of the resin monomers into the etched dentin $(11,12)$. Thus, a few studies have suggested the use of sonic devices so that the movement of the applicator would transfer energy to the resin monomers, allowing them to reach areas not touched by the applicator $(13,14)$. Furthermore, the sonic vibrations create pressure waves that result in the formation of microscopic bubbles, pushed onto the dentinal walls, facilitating the diffusion of the monomers and evaporation of the solvents (13-15).

In addition, in the cementation of fiberglass posts using conventional resin cements, the device would be suitable both for the active application of the adhesive system as well as the accommodation of the post and enhancement of the resin cement flow during luting. It is known that the insertion of cement into the post space using the long tips of Centrix syringes or Lentulo drills tends to result in more regular and homogeneous cement films $(16,17)$. Therefore, there is a hypothesis that the homogeneity and quality of the layers formed by applying adhesive system and resin cement using a sonic device would improve the bond strength. Further, there are no studies on the use of a sonic device to enhance to resin cement film formed after the accommodation of the post.

Hence, the aim of the present study was to evaluate the effect of sonic vibrations on the bond strength of fiberglass posts bonded to root dentin as measured by the pull-out test. The tested hypothesis was that the sonic vibrations during the luting procedure (adhesive application, post accommodation, or both) would improve the bond strength of fiberglass posts in endodontically treated teeth.

\section{Material and Methods}

Fifty-six freshly extracted bovine incisors with anatomically similar root segments and fully developed apices were selected and cleaned. The roots were cut to a uniform length of $14 \mathrm{~mm}$ from the apical end, using a 
low-speed diamond saw (Isomet 1000; Buehler, Lake Bluff, IL). A single operator prepared all the root canals using the crown-down technique with rotatory Profile universal files (Dentsply Maillefer, Ballaigues, Switzerland). The working length was $14 \mathrm{~mm}$ and apical enlargement was performed using file sizes of up to 100 . After every change of instrument, the canal was irrigated alternately with 1 $\mathrm{mL} 1 \%$ sodium hypochlorite and 17\% EDTA solutions. The roots were dried with paper points (Dentsply Maillefer) and filled with AH Plus (Denstply DeTrey, Konstanz, Germany); tapered gutta-percha points were used and Tagger's hybrid technique was employed.

All the post spaces were prepared to a depth of 10 $\mathrm{mm}$ using special drills supplied by the manufacturer of the used fiber post system (Whitepost DC3; FGM, Joinville, $\mathrm{SC}$, Brazil). The roots were rinsed with water to remove the remaining debris and the excess moisture was removed with paper points. The roots were then divided into four groups ( $n=12)$ (Table 1$)$

The used adhesive was a two-step etch-and-rinse adhesive (Ambar, FGM), and the samples were treated as per the manufacturer's instructions. For groups $\mathrm{C}$ and $\mathrm{SP}$, the adhesive system was applied actively and vigorously to the dentin walls using a microbrush (long; FGM). For groups SA and SASP, the adhesive was applied by a microbrush attached to the sonic device (Smart Sonic Device $241 \mathrm{~Hz}$; FGM). Two layers of the adhesive system were applied twice (10 s each) for each sample and light-cured for $20 \mathrm{~s}$ at 1,100 $\mathrm{mW} / \mathrm{cm}^{2}$ (Poly Wireless; Kavo, Joinville, SC, Brazil).

The fiberglass posts (White DC3, FGM) were cleaned with 70\% alcohol. Next, the dual-cured resin cement (AllCem Core, FGM) was applied with an Automix/Point tip applicator. For groups $C$ and $S A$, the posts were positioned in the post spaces using digital pressure, while for groups SP and SASP, the posts were accommodated and sonic vibration was applied, for $10 \mathrm{~s}$, using a special tip placed on top of the post. The excess cement was removed and the roots were light-cured for $40 \mathrm{~s}$.

Next, the specimens were stored in water at $37^{\circ} \mathrm{C}$ for $24 \mathrm{~h}$ and then were subjected to the pull-out tests in a

Table 1. Distribution of samples into various groups

\begin{tabular}{lc}
\hline Group & Protocol \\
\hline C & $\begin{array}{c}\text { Conventional application of adhesive } \\
\text { system and accommodation of post }\end{array}$ \\
SA & $\begin{array}{c}\text { Sonic application of adhesive system and } \\
\text { conventional accommodation of post }\end{array}$ \\
SP & $\begin{array}{c}\text { Conventional application of adhesive system } \\
\text { and sonic accommodation of post }\end{array}$ \\
SASP & $\begin{array}{c}\text { Sonic application of adhesive system } \\
\text { and accommodation of post }\end{array}$ \\
\hline
\end{tabular}

universal testing machine (EMIC, São José dos Pinhais, PR, Brazil) with a cross-head speed of $0.5 \mathrm{~mm} / \mathrm{min}$. The data were statistically analyzed using ANOVA and Tukey's test $\alpha=0.05$ ).

After the completion of the pull-out tests, the surfaces of the specimens were examined under a stereoscope (magnification 57x) (SZX9; Olympus, Tokyo, Japan) in order to classify the failure mode. The surfaces with $50 \%$ or more of their area covered with cement were classified as Score 1, while those with less than $50 \%$ of their area covered with cement were classified as Score 2.

Eight bovine incisors were randomly distributed into four groups ( $n=2)$ and treated according to the abovementioned protocols. Then, $24 \mathrm{~h}$ after the luting process, the roots were sectioned perpendicular to the long axis using a diamond saw (Isomet, Buehler, Lake Bluff, IL, USA) to obtain 61 -mm thick slices.

The sections were gently decalcified (treatment with $37 \%$ phosphoric acid for $30 \mathrm{~s}$ followed by washing and gentle air-drying) and deproteinized (immersion in a $2 \%$ sodium hypochlorite solution for $120 \mathrm{~s}$ ). The specimens were then dehydrated with alcohol, gold sputtered and observed in a scanning electron microscope (SEM) (Philips 515; Philips, Amsterdam, The Netherlands) at different magnifications. Serial SEM photomicrographs of the canal walls were taken at the 1-, 4.5-, and 8-mm levels (500x magnification). The photomicrographs were aligned to form a continuous horizontal examination strip at the three levels. Irrespective of the number of photomicrographs required to form a complete strip, each strip was subdivided into seven "assessment units." For each assessment unit, two different operators in a double-blind setup evaluated the resin cement film at the three different levels and checked for the presence or absence of gaps a) inside the resin cement, b) between the dentinal walls and the resin cement, and c) between the resin cement and the post.

The normality of the data was confirmed by the ShapiroWilk test and their homoscedasticity was tested using Levene's test for homogeneity of variances. The pull-out bond strength values were subjected to one-way ANOVA and Tukey's test $(\alpha=0.05)$.

\section{Results}

The mean values and standard deviations of the pullout bond strengths are in Table 2. The statistical analysis of data showed that there were significant differences between the groups $(p<0.05)$. There were no statistically significant differences between groups $\mathrm{SP}, \mathrm{SA}$, and $\mathrm{C}$. The protocol $\mathrm{C}=\mathrm{SA}=\mathrm{SASP}$ had also similar values.

An analysis of the SEM images of the samples showed that, irrespective of the group and tooth third, all the samples exhibited structural discontinuities, like bubbles 
and gaps. These discontinuities were more evident at the interface between resin cement and dentin.

There was no significant difference among the groups C, SA and SASP. However, group SP exhibited the most homogeneous resin cement films, both when compared to the other groups as for the different tooth thirds (Fig. 1). In the case of groups $C, S A$, and SASP, the apical thirds showed a greater number of irregularities than did the middle and cervical sections (Fig. 2).

Regarding the failure mode, all groups showed more score 2 failures, where $50 \%$ or more of the post area remained with the luting cement (Fig. 3).

\section{Discussion}

The clinical success of bonded fiberglass posts relies mainly on the fact that their retention rate is higher than the one for adhesive bonding, due to the friction between the posts and the post space walls (18). The pull-out test is an appropriate mechanical test for determining the strength of the bond formed with root dentin (19) and is considered a clinically relevant test. At the top of the post, tensile stress prevails, while shear stress dominates the long axis of the post. On the other hand, the push-out test may yield overestimated results, since only a small bonded area is analyzed during the test $(20,21)$.
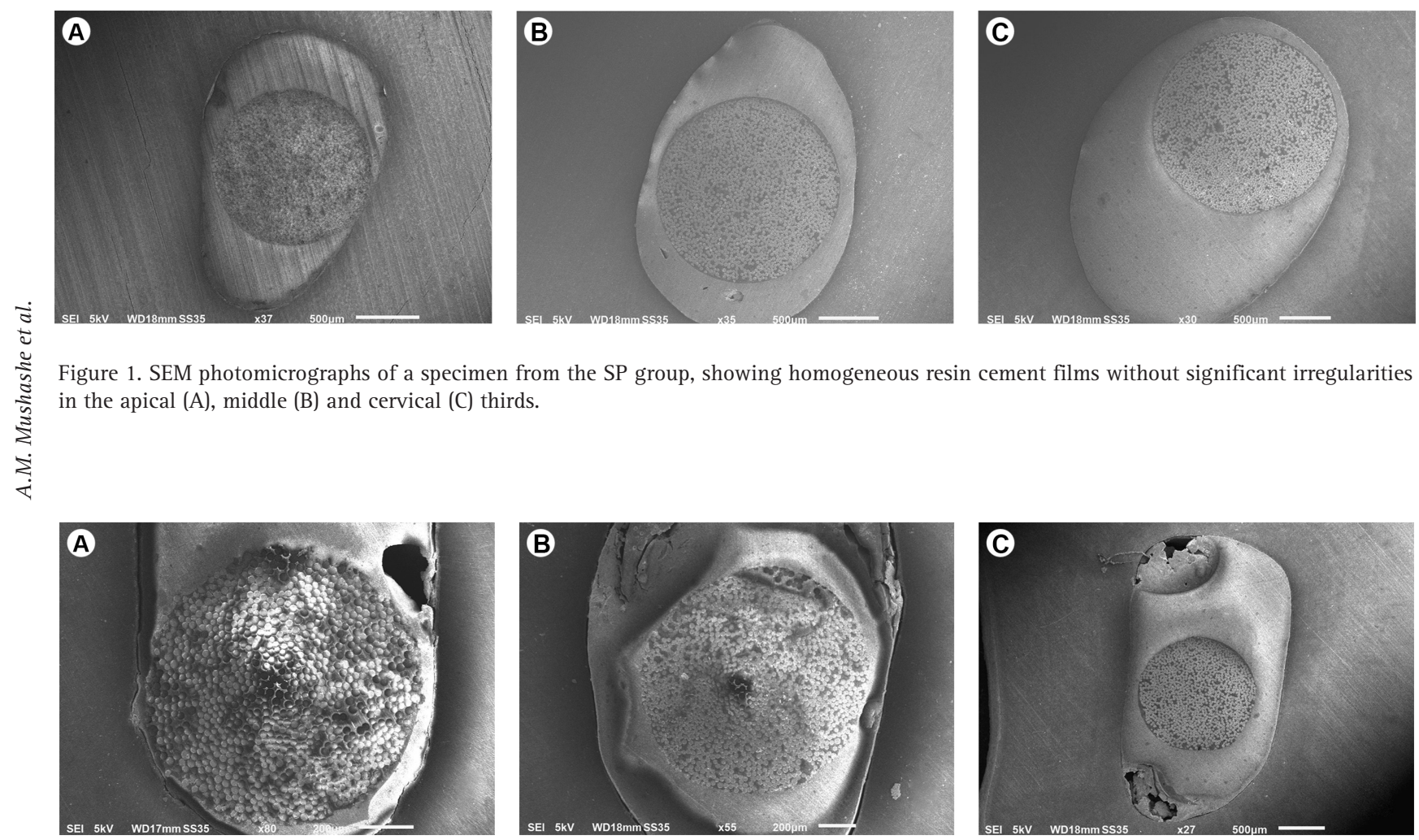

Figure 1. SEM photomicrographs of a specimen from the SP group, showing homogeneous resin cement films without significant irregularities in the apical (A), middle (B) and cervical (C) thirds.

Figure 2. SEM photomicrographs of apical specimens from groups C (A), SA (B) and SASP (C), showing the presence of bubbles and gaps in the resin cement films.

Table 2. Mean (N) and standard deviation (SD) values for the different groups after the pull-out test $(\mathrm{n}=12)$

\begin{tabular}{lc}
\hline Group & Mean $( \pm$ SD $)$ \\
\hline C & $121.4 \pm 60.6^{\mathrm{ab}}$ \\
SA & $127.6 \pm 31.8^{\mathrm{ab}}$ \\
SP & $156.4 \pm 41.3^{\mathrm{a}}$ \\
SASP & $90.9 \pm 27.1^{\mathrm{b}}$ \\
\hline
\end{tabular}

Values with different superscript letters are significantly different $(\mathrm{p}<0.05)$.

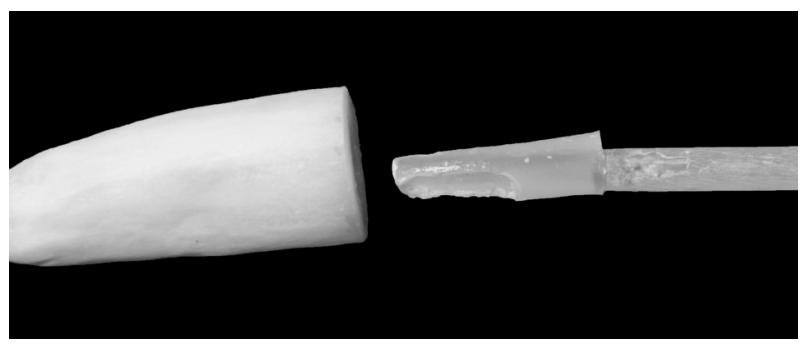

Figure 3. Stereoscopic analysis of the luted surface of a specimen after the pull-out test; more than 50\% of the area is covered with cement (score 2). 
Cavity configuration, poor access and visualization of the post space, and difficulty in controlling the moisture $(4,5)$ are reasons to explain the fact that the main cause of failure of these posts is their debonding from the root dentin (7-9). This was also evident in the results of the present study, when the post surfaces were analyzed after the pull-out test. For all the specimens, $50 \%$ or more of the area was covered with cement (score 2). Thus, all the samples exhibited adhesive failure between the cement and the root dentin, as already shown in other similar studies $(19,20)$. Most of the adhesive failures are possibly related to the type of teeth used in this study. Using bovine teeth may result in an increase of the cement layer thickness, because of the larger root canal diameter. The resulting increase in the polymerization shrinkage caused by the thick resin cement film may also lead to adhesive failure. However, bovine teeth allow for the standardization of the experimental setup, since differences in age and occlusal and diet conditions can be avoided (22). Furthermore, bovine teeth have been used in other similar studies to determine the bond strength of fiberglass posts (23).

There was no statistical difference between groups C, SA, and SASP. This discards the hypothesis that the use of sonic vibrations during the luting procedure would increase the final bond strength. A few studies have shown that the use of sonic vibrations during adhesive application may aid the agitation of the fluids, improving penetration of the resin monomers into the dentin as well as increasing the evaporation of solvents (13-15). Cuadro-Sanchez et al. (24) found that the use of Smart Sonic Device at a $170 \mathrm{~Hz}$ frequency enhanced the push-out bond strength when used to apply different adhesive systems for cementation of fiberglass posts. On the other hand, Mena-Serrano et al. (13) reported that the application of sonic vibrations at $170 \mathrm{~Hz}$ in the case of a self-etching adhesive had no effect on the bond strength between occlusal dentin and a resin composite. The differences in the results obtained in this study and other similar ones can be ascribed to the differences in the used oscillatory frequencies. In the present study, the frequency was $241 \mathrm{~Hz}$, the lowest possible in the used device. Even though there were no significant differences between groups $C$ and SA in this study, the use of a sonic device may reduce the variations in the applied pressure by different operators during the manual application of the adhesive system, ensuring greater uniformity during the application process and lowering the sensitivity of the technique.

To the authors' knowledge, no study has evaluated the use of a sonic device for accommodating posts during the luting procedure. This study found no statistical difference between the C and SP groups. However, despite the lack of statistical differences between the groups microscopic analysis revealed that the samples in group SP showed more uniform cement films in all thirds, compared to the samples of the control group. During the fiberglass post cementation process, it is possible that air is incorporated into the cement mixture. The expansion or contraction of the resulting air microbubbles may eventually lead to the weakening of the cement layer (25). Cement insertion using Lentulo drills, Centrix syringes and elongation tips tends to produce cement films that are more homogeneous and with less bubbles $(16,17)$. The sonic device used in the present study also resulted in films with less defects. Thus, it may be concluded that the use of sonic vibrations during the post accommodation process enhanced the cement flow, even though it did not have an effect on the bond strength. Hence, studies that involve longer evaluation periods and aging methods are required.

In this study, a statistical difference was observed between groups SP and SASP, suggesting that the concomitant use of sonic vibrations for both application of the adhesive system and for fiberglass post accommodation affected negatively the pull-out bond strength. A possible explanation for this phenomenon is that, under the conditions employed in this study, the vibrations disturbed the hybrid layer formed between the root dentin and the adhesive system, causing the adhesive interface to collapse.

Based on the results obtained in this study, it may be concluded that the use of sonic vibrations for applying the adhesive system or for fiberglass post accommodation during luting did not affect the pull-out bond strength. However, it had a negative effect when used concurrently for both procedures.

\section{Resumo}

Vibrações sônicas podem melhorar a resistência e a durabilidade da união de pinos de fibra de vidro, melhorando a penetração do sistema adesivo à dentina, bem como o escoamento do cimento. 0 objetivo deste estudo foi avaliar o efeito da vibração sônica na resistência de união de pinos de fibra de vidro à dentina radicular, através de ensaio pull out. Raizes bovinas tratadas endodonticamente foram preparadas e divididas aleatoriamente em quatro grupos $(n=12)$ : Grupo $C$ - cimentação convencional, (controle); Group SA - vibração sônica (Smart Sonic Device ${ }^{\circledR}$ FGM) do sistema adesivo e assentamento convencional do pino; grupo SP - aplicação convencional do sistema adesivo e vibração sônica no assentamento do pino; e SASP - vibração sônica do sistema adesivo e no assentamento do pino. Os retentores foram limpos, tratados com silano e sistema adesivo (Ambar, FGM) e cimentados com cimento resinoso dual (Allcem Core, FGM). Após $24 \mathrm{~h}$ as amostras foram submetidas ao teste mecânico e análise de falha. Amostras representativas foram avaliadas sob microscópio eletrônico de varredura, para avaliação da linha de cimentação. Os resultados foram analisados por meio de análise de variância e teste de Tukey $(\alpha=5 \%)$. Os resultados obtidos foram: SASP $(90,9 \pm 27,1 \mathrm{~N}, \mathrm{C}(121,4 \pm 60,6 \mathrm{~N}), \mathrm{SA}(127,6 \pm 31,8 \mathrm{~N})$ e SP $(156,4 \pm 41,3 \mathrm{~N})$. 
A vibração sônica para aplicação apenas do sistema adesivo ou pino não afetou a resistência de união, entretanto interferiu negativamente quando utilizada para ambos procedimentos.

\section{References}

1. Duret BRM, Duret F. A new concept of corono-radicular reconstruction, the Composipost. Le Chir Dent France 1990;540:131-141.

2. Bateman G1, Ricketts DN, Saunders WP. Fibre-based post systems: a review. Br Dent J 2003;195:43-48.

3. Liu X, Zhang Y, Zhou Z, Ma S. Retrospective study of combined splinting restorations in the aesthetic zone of periodontal patients. $\mathrm{Br}$ Dent J 2016;220:241-247.

4. Hayashi M, Ebisu S. Key factors in achieving firm adhesion in post-core restorations. Jpn Dent Sci Rev 2008;44:22-28.

5. Mallmann $A$, Jacques $L$, Valandro $L F$, Mathias $P$, Muench $A$. Microtensile bond strength of light- and self-cured adhesive systems to intraradicular dentin using a translucent fiber post. Oper Dent 2005;30:500-506.

6. Chen $Q$, Wei XY, Yi M, Bai YY, Cai Q, Wang XZ. Effect on the bond strengths of glass fiber posts functionalized with polydopamine after etching with hydrogen peroxide. Dent Mater J 2015;34:740-745.

7. Fredriksson M, Astback J, Pamenius M, Arvidson K. A retrospective study on 236 patients with teeth restored by carbon fiber-reinforced epoxy resin posts. J Prosthet Dent 1998;80:151-157.

8. Chieruzzi M, Pagano S, Pennacchi M, Lombardo G, D'Errico P, Kenny JM. Compressive and flexural behaviour of fibre reinforced endodontic posts. J Dent 2012;40:968-978.

9. Rasimick BJ, Wan J, Musikant BL, Deutsch AS. A review of failure modes in teeth restored with adhesively luted endodontic dowels. J Prosthodont 2010;19:639-646.

10. Mehta SB, Millar BJ. A comparison of the survival of fibre posts cemented with two different composite resin systems. Br Dent J 2008;205:E23.

11. Da Silva EM, Glir DH, Gill AW, Giovanini AF, Furuse AY, Gonzaga CC. Effect of chlorhexidine on dentin bond strength of two adhesive systems after storage in different media. Braz Dent J 2015;26:642-647.

12. Loguercio $A D$, Raffo J, Bassani F, Balestrini $H$, Santo $D$, do Amaral $R C$, et al.. 24-month clinical evaluation in non-carious cervical lesions of a two-step etch-and-rinse adhesive applied using a rubbing motion. Clin Oral Investig 2011;15:589-596.

13. Mena-Serrano A, da Costa TRF, Patzlaff RT, Loguercio AD, Reis A. Effect of sonic application mode on the resin-dentin bond strength and dentin permeability of self-etching systems. J Adhes Dent
2014,16:435-440.

14. Mena-Serrano A, Garcia EJ, Loguercio AD, Reis A. Effect of sonic application mode on the resin-dentin bond strength and nanoleakage of simplified self-etch adhesive. Clin Oral Investig 2014;18:729-736.

15. Loguercio AD, Stanislawczuk R, Mena-Serrano A, Reis A. Effect of 3 -year water storage on the performance of one-step self-etch adhesives applied actively on dentine. J Dent 2011;39:578-587.

16. Michida SM, Souza RO, Bottino MA, Valandro LF. Cementation of fiber post: influence of the cement insertion techniques on the bond strength of the fiber post-root dentin and the quality of the cement layer. Minerva Stomatol 2010;59:633-636.

17. Watzke $R$, Frankenberger $R$, Naumann M. Probability of interface imperfections within SEM cross-sections of adhesively luted GFP. Dent Mater 2009;25:1256-1263.

18. Pirani C, Chersoni S, Foschi F, Piana G, Loushine RJ, Tay FR, et al.. Does hybridization of intraradicular dentin really improve fiber post retention in endodontically treated teeth? J Endod 2005;31:891-894.

19. D'Arcangelo $C$, Cinelli $M$, de Angelis $F$, D'Amario $M$. The effect of resin cement thickness on the pullout strength of fiber-reinforced system. J Prosthet Dent 2007,98:193-198.

20. Giachetti L, Grandini S, Calamai P, Fantini G, Russo DS. Translucent fiber post cementation using light- and dual-curing adhesive techniques and a self-adhesive material: push-out test. J Dent 2009;37:638-642.

21. Gomes GM, de Rezende EC, Gomes OMM, Gomes JC, Loguercio AD, Reis $A$. Influence of the resin cement thickness on bond strength and gap formation of fiber posts bonded to root dentin. J Adhes Dent 2014;16:71-78.

22. Wrbas KT, Altenburger MJ, Schirrmeister JF, Bitter K, Kielbassa AM. Effect of adhesive resin cements and post surface silanization on the bond strengths of adhesively inserted fiber posts. J Endod 2007;33:840-843.

23. Nova V, Karygianni L, Altenburger MJ, Wolkwitz M, Kielbassa AM, Wrbas KT. Pull-out bond strength of a fibre-reinforced composite post system luted with self-adhesive resin cements. J Dent 2013;41:1-7.

24. Cuadro-Sanchez J, Szesz A, Hass V, Patzlaff RT, Reis A, Loguercio AD. Effect of sonic application of adhesive systems on bonding fiber posts to root canals. J Endod 2014,40:1201-1205.

25. Lyons KM, Rodda JC, Hood JA. The effect of environmental pressure changes during diving on the retentive strength of different luting agents for full cast crowns. J Prosthet Dent 1997;78:522-527.

Received June 2, 2016 Accepted November 9, 2016 